\title{
TEMPO DE CONSERVAÇÃO PÓS-COLHEITA DA ALFACE CRESPA SUBMETIDA A DOSES DE SILICATO DE MAGNÉSIO
}

\author{
Vinicius de Almeida Silva, Patricia Reiners Carvalho \\ Universidade do Oeste Paulista - UNOESTE, Curso de Agronomia, Presidente Prudente - SP. E-mail: \\ patricia@unoeste.br
}

\section{RESUMO}

A alface é a hortaliça folhosa mais consumida no mundo, tendo como frescor e limpeza as principais características buscadas pelo consumidor. Com esse grande consumo é extremamente importante diminuir perdas pós-colheita que são um grande problema principalmente para frutas e hortaliças. Com o objetivo de analisar a conservação pós-colheita da alface crespa recebendo doses foliares de silicato de magnésio ( $\mathrm{SiMg}$ ), foi conduzido o experimento na Universidade do Oeste Paulista, Presidente Prudente - SP, no ano de 2014. O delineamento utilizado foi o inteiramente casualizado, utilizando cinco doses de $\operatorname{SiMg}\left(0,0 ; 0,16 ; 0,32 ; 0,48 ; 0,64\right.$ g.L $\left.^{-1}\right)$, aplicados via foliar semanalmente por 3 vezes. Os dados de peso, altura, e diâmetro foram submetidos à análise de variância pelo programa estatístico SISVAR, sendo as médias comparadas pelo teste de Tukey a $5 \%$ de probabilidade, e qualidade pós-colheita avaliadas através de notas dadas as plantas, as notas médias obtidas na última avaliação pós-colheita, aos 25 dias, foram submetidas à análise de regressão para as diferentes concentrações de SiMg. Não se obteve diferenças significativas em relação a peso, altura e diâmetro da alface crespa, porém a dosagem de $0,32 \mathrm{~g} \cdot \mathrm{L}^{-1}$ apresentou maior longevidade de conservação das folhas.

Palavras-chave: Adubação foliar. Longevidade das folhas. Hortaliças

\section{SHELF-LIFE POST-HARVEST OF LETTUCE CURLY UNDER DOSE OF MAGNESIUM SILICATE}

\begin{abstract}
Lettuce is the most consumed leafy vegetable in the world, with the freshness and cleaning the main characteristics sought by the consumer. With this large consumption is extremely important to reduce post-harvest losses which are a big problem especially for fruits and vegetable. With the objective of analyzing the post-harvest conservation of curly lettuce receiving leaf doses of magnesium (SiMg) silicate, the experiment was conducted at the Universidade do Oeste Paulista, Presidente Prudente - SP, in 2014. The experimental design was completely randomized, using five doses of SiMg $(0.0,0.16,0.32,0.48,0.64 \mathrm{~g} \mathrm{L-1})$ applied to the leaves weekly for 3 times. Data on weight, height, and diameter were subjected to analysis of variance and the averages were compared by Tukey test and post-harvest quality assessed through notes given the plants, the average marks obtained in the last post-harvest assessment at 25 days, were subjected to regression analysis for the different concentrations of SiMg. No significant differences were obtained in relation to weight, height and diameter of curly lettuce, but the dosage of $0.32 \mathrm{~g} \mathrm{L-1}$ had greater longevity conservation of leaves.
\end{abstract}

Keywords: Foliar fertilization. Longevity of leaves. Vegetable crops. 


\section{INTRODUÇÃO}

A alface (Lactuca sativa L.), originária da Ásia e trazida para o país pelos portugueses no século XVI, é a hortaliça folhosa de maior consumo no Brasil, sendo seu frescor e limpeza as características mais valorizadas pelo consumidor. Cada paulistano consome quase dois quilos de alface por ano, sendo $40 \%$ dos seus gastos totais com verduras, destinados à compra dessa hortaliça (CEAGESP, 2012). A cultura da alface apresenta alto grau tecnológico, sendo comuns as práticas de produção em estufa, hidroponia e cultivo orgânico, que permitem obter verduras de qualidade durante $o$ ano todo.

Quando se pensa em aumentar a produtividade nas hortas, logo pensamos em aumentar a área agrícola e um controle de pragas e doenças eficientes. Para suprir a necessidade da população que cada vez cresce mais, é sim necessário aumentar a produtividade, porém é de suma importância a diminuição de perdas pós-colheita e encontrar novos métodos de atingir um maior tempo de conservação dos alimentos colhidos, principalmente no caso de hortaliças como, por exemplo, a alface, que é um alimento sensível a danos físicos e também muito sensível a perda de água, sendo composto por mais que $90 \%$ de água.

O uso de silício na adubação mostra vários benefícios às plantas, como o aumento de produtividade e proteção a pragas e doenças. Está também associado a regular a perda de água na planta, e aumento da rigidez da estrutura dos tecidos pelo acúmulo de silício na cutícula da folha (RODRIGUES et al. 2011).

Devido à busca de dados sobre a resposta da alface tratada com silicato de magnésio em relação a sua qualidade pós-colheita, esse trabalho foi realizado.

\section{MATERIAL E MÉTODOS}

O experimento foi conduzido na horta da Universidade do Oeste Paulista - UNOESTE, Presidente Prudente - SP. O clima da região, segundo a classificação de Köppen, é do tipo Cwa, que significa ser tropical com estação chuvosa e quente bem definida entre os meses de setembro a março, e inverno seco com temperaturas amenas entre os meses de abril a setembro.

O período experimental foi do dia 17/03/2014 (semeadura), até dia 09/06/2014 (última análise pós-colheita). Foram selecionadas 50 mudas de alface crespa (Lactuca sativa L.) com o mesmo padrão de porte e idade, as quais foram obtidas de sementes germinadas em bandejas de isopor e transplantadas para sacos plásticos com 15 dias após a germinação e com sete cm de altura, no viveiro de mudas da horta da UNOESTE. A irrigação foi realizada diariamente e manualmente. As adubações aplicadas no dia 23/04/2014 a primeira dose, e dia 08/05/2014 a 
segunda dose, via foliar, utilizando 1grama do fertilizante formulado 10-10-10 por planta, o substrato dos saquinhos sendo composto por Latossolo e matéria orgânica na proporção 1:1.

O delineamento experimental utilizado foi em blocos casualizados, com cinco tratamentos e dez repetições, e um saquinho com uma planta por parcela. Os tratamentos consistiram de aplicações com silicato de magnésio (SiMg), composto de 65\% de $\mathrm{SiO}_{2}$ e $14 \%$ de $\mathrm{MgO}$, pulverizadas manualmente com 0,004 L de cada solução por planta, nas seguintes concentrações: 0,0 (controle); 0,$16 ; 0,32 ; 0,48$ e $0,64 \mathrm{~g} \mathrm{~L}^{-1}$, sendo realizada a cada sete dias via foliar, totalizando 3 aplicações, sendo a primeira com 14 dias após o transplante das bandejas para os saquinhos, ou seja 21 dias após a semeadura.

Aos 65 dias após a semeadura foram avaliadas nas mudas de alface: a massa fresca total (g/planta); circunferência e comprimento do caule da cabeça comercial $(\mathrm{cm})$, e após 70 dias da semeadura foi realizada a primeira análise de conservação pós-colheita em câmara fria a $5{ }^{\circ} \mathrm{C} \pm 2$ ${ }^{\circ} \mathrm{C}$ avaliada através de notas. Nota 0 - cabeças com apenas duas folhas ou menos (sem condição de comercialização); nota 1 - cabeças com mais de 3 folhas deterioradas (ainda aptas à comercialização); nota 2 - cabeças com no máximo 3 folhas deterioradas (aptas à comercialização), realizadas aos 5, 10, 15,20 e 25 dias após colheita sob condições de refrigeração.

Os dados de peso, altura, e diâmetro foram submetidos à análise de variância, sendo as médias comparadas pelo teste de Tukey ao nível de $5 \%$ de probabilidade utilizando o programa "SISVAR" versão 4.2 (FERREIRA, 2007).

As notas médias obtidas na última avaliação pós-colheita, ou seja aos 25 dias, foram submetidas à análise de regressão nas diferentes concentrações de SiMg aplicado nas plantas de alface.

\section{RESULTADOS E DISCUSSÃO}

Pode se observar no trabalho realizado e aqui descrito, que o SiMg traz inúmeros benefícios já comprovados para diversas culturas como alface, milho, arroz, trigo, etc avaliados por Epstein (2001); Resende et. al., (2005), porém em relação a alface crespa, não trouxe diferenças significativas em relação a produtividade com as doses utilizadas e condições avaliadas.

De acordo com a Tabela 1 os dados de peso, altura e diâmetro da alface crespa submetidas a diferentes doses de SiMg, não obtiveram diferenças estatísticas significativas de acordo com o teste de Tukey a 5\%. 
Tabela 1. Concentração de Silicato de Magnésio em relação ao peso, altura e diâmetro da alface crespa.

\begin{tabular}{|c|c|c|c|c|}
\hline $\begin{array}{l}\text { Concentração } \\
\text { g. } \mathrm{L}^{-1}\end{array}$ & SiMg & Peso (gramas) & Altura $(\mathrm{cm})$ & Diâmetro $(\mathrm{cm})$ \\
\hline 0,0 & & $66,18 \mathrm{a}$ & $32,44 a$ & $41 \mathrm{a}$ \\
\hline 0,16 & & $98,25 \mathrm{a}$ & $36,71 \mathrm{a}$ & $46,20 \mathrm{a}$ \\
\hline 0,32 & & $107,80 \mathrm{a}$ & $31,20 a$ & $44,11 \mathrm{a}$ \\
\hline 0,48 & & 98,32 a & $33,50 \mathrm{a}$ & 42,62 a \\
\hline 0,64 & & $72,82 \mathrm{a}$ & $30,52 \mathrm{a}$ & $38,57 \mathrm{a}$ \\
\hline CV \% & & 35 & 19 & 29 \\
\hline
\end{tabular}

Já em relação a pós-colheita, os tratamentos receberam o mesmo método de conservação, a refrigeração em geladeira, buscando aproximar ao máximo a situação encontrada na casa dos consumidores.

Com relação à pós-colheita realizada aos 25 dias após a colheita, observou-se diferenças significativas entre as concentrações de SiMg sendo que a dose de 0,32 g. $\mathrm{L}^{-1}$ obteve os melhores resultados em relação a testemunha e os outros tratamentos. Observando a Figura 1, detectamos que a dose de 0,32 g. $\mathrm{L}^{-1}$ aos 25 dias após a colheita, foi a única que obteve nota de 1,1, ou seja, ainda existiam plantas aptas a comercialização.

Apesar de não ser considerado elemento essencial às plantas, o Si tem demonstrado efeito benéfico em diversas culturas aumentando a rigidez celular, conferindo proteção às plantas, aumento da capacidade fotossintética, tolerância à seca, Epstein (2001), verificou que além de propiciar melhor conservação pós-colheita, como por exemplo, da alface (Resende et al., 2005) e de flores de Dendrobio nobile (Reiners, 2013), o que provavelmente auxiliariam em uma maior conservação e possivelmente viabilizaram esta resposta positiva da aplicação de silicato, na maior conservação pós-colheita da alface crespa. Os resultados obtidos evidenciaram ser o silício importante para uma melhor conservação pós-colheita da alface crespa. 
Figura 1. Análise de regressão de doses de Silicato de Magnésio em relação as médias de notas na conservação pós colheita da alface crespa

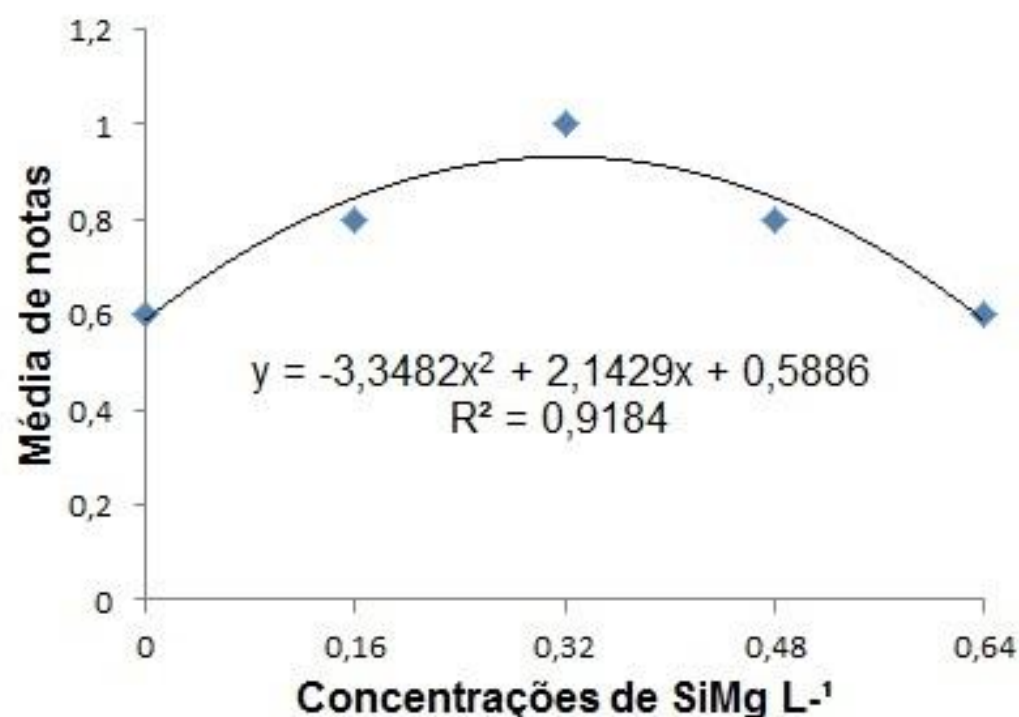

\section{CONCLUSÕES}

Concluiu-se que o SiMg nas doses e condições testadas não trouxeram efeitos significativos no crescimento e desenvolvimento da alface crespa.

$\mathrm{Na}$ qualidade pós-colheita, a dose de $0,32 \mathrm{~g} \cdot \mathrm{L}^{-1}$ de $\mathrm{SiMg}$ apresentou as melhores notas na última análise, apresentando plantas aptas a comercialização.

\section{REFERÊNCIAS}

ALBUQUERQUE, C. Cálcio e silício beneficiam gérbea depois da colheita. 2012. Disponível em: < http://www.usp.br/agen/?p=88741>. Acesso: 13/06/2014

AMARAL, J.G. Construção e fixação de conceitos alternativos na produção de hortaliças em ambiente protegido em função da cobertura do solo e adubação orgânica. 2005. Disponível em: <http://www.ia.ufrrj.br/ppgea/dissertacao/Joaquim\%20Gonzaga\%20do\%20Amaral.pdf> . Acesso: 05/06/2014

CEAGESP. Alface. 2012. Disponível em:< http://www.ceagesp.gov.br/produtos/produtos/alface>. Acesso: 05/06/2014

EMBRAPA. O Silício e a resistência das plantas ao ataque de fungos patogênicos. 2005. Disponível em: <http://www.cpao.embrapa.br/portal/artigos/artigos/artigo1.html\#sdfootnote1sym>. Acesso em: 05/06/2014

EPSTEIN, E. Silicon in plants: facts vs. concepts. In: DATNOFF, L. E.; SNYDER, G. H.; KORNDÖRFER, G. H. (Ed.). Silicon in agriculture. Amsterdam: Elsevier, 2001. p. 1-15. http://dx.doi.org/10.1016/S0928-3420(01)80005-7 
FERREIRA, D.F. Sisvar: sistema de análise de variância para dados balanceados, versão. 5.1. Software estatístico, Lavras: DEX/ UFLA, 2007.

FERREIRA, R.L.F. et al. Avaliação de cultivares de alface adubadas com Silifértil . Caatinga, v.22, n.2, p.5-10, 2009.

GIRÃO, J.E. Aula sobre alface no Curso de Engenharia Agronômica na UFPI. 2010. Disponível em: <http://www.ebah.com.br/content/ABAAAAOK4AF/aula-sobre-alface>. Acesso: 06/06/2014

KORNDORFER, G.H. Uso do silício na agricultura. 2002. Disponível em: <http://www.dpv24.iciag.ufu.br/Silicio/Efeitos/Efeitos.htm>. Acesso: 05/06/2014

PLANETA ORGÂNICO. Pós colheita: conservação de Frutas e Hortaliças. 2010. Disponível em: $<$ http://planetaorganico.com.br/site/index.php/pos-colheita-conservacao-de-frutas-e-hortalicas3/?s=pos\%20colheita.\%20conserva\%C3\%A7\%C3\%A30\%20de\%20frutas\%20e\%20hortali\%C3\%A7as >. Acesso: 06/06/2014

REINERS, P. Efeito do silício na qualidade de flores de Dendrobium nobile (Orchidaceae). 2013. Disponível em: <http://www.uel.br/revistas/uel/index.php/semagrarias/article/view/10735>. Acesso: 13/06/2014

RESENDE, G.M.; YURI J.; SOUZA R.J. Épocas de plantio e doses de silício no rendimento de alface tipo americana. 2005.2 Disponível em: $<$ http://www.scielo.br/scielo.php?script=sci arttext\&pid=S0102-05362007000300026>. Acesso: $05 / 06 / 2014$

RODRIGUES, F.A. et al. Silício: Um elemento benéfico e importante para as plantas. 2011. Disponível em: < http://www.ipni.net/publication/iabrasil.nsf/0/66D3EE234A3DA5CD83257A8F005E858A/\$FILE/Page14-20-134.pdf>.

Acesso: 05/06/2014 